\title{
Evaluation of health-related quality of life of Covid-19 patients: a hospital-based study in South Central Ethiopia
}

Abdene Weya Kaso ${ }^{1 *}$, Gebi Agero ${ }^{2}$, Zewdu Hurisa ${ }^{3}$, Taha Kaso ${ }^{4}$, Helen Ali Ewune ${ }^{1}$ and Alemayehu Hailu $5^{*}$ (D)

\begin{abstract}
Background: Covid-19 causes a wide range of symptoms in patients, ranging from mild manifestations to severe disease and death. This study assessed the health-related quality of life (HRQOL) and associated factors of Covid-19 patients using primary data from confirmed cases in South Central Ethiopia.

Methods: We employed a facility-based, cross-sectional study design and conducted the study at the Bokoji Hospital Covid-19 treatment centre. A structured questionnaire and the EQ-5D-3L scale were used to collect the data for analysis. The HRQOL results measured by the EQ-5D-3L tool were converted to a health state utility (HSU) using the Zimbabwe tariff. The average health utility index and HSU-visual analogue scale across diverse sociodemographic and clinical characteristics were compared using the Mann-Whitney $U$ test or Kruskal-Wallis test. We employed a multiple linear regression to examine factors associated with HSU values simultaneously. The data were analysed using STATA version 15.
\end{abstract}

Results: The overall mean HSU score from the EQ-5D was 0.688 (SD: 0.285), and the median was 0.787 (IQR 0.596, 0.833). The mean HSU from the visual analogue scale score was 0.69 (SD: 0.129), with a median of $0.70($ IQR $0.60,0.80)$. Those who received dexamethasone and intranasal oxygen supplement, those with comorbidity, those older than 55 years and those with a hospital stay of more than 15 days had significantly lower HSU scores than their counterparts $(p<.001)$.

Conclusion: Covid-19 substantially impaired the HRQOL of patients in Ethiopia, especially among elderly patients and those with comorbidity. Therefore, clinical follow-up and psychological treatment should be encouraged for these groups. Moreover, the health utility values from this study can be used to evaluate quality adjusted life years for future cost-effectiveness analyses of prevention and treatment interventions against Covid-19.

Keywords: Quality of life, HRQOL, Covid-19, Arsi Zone, Ethiopia

\section{Introduction}

Coronavirus disease 2019 (Covid-19) is first discovered in China's Wuhan Province in December 2019. According to the World Health Organization (WHO) (April

\footnotetext{
*Correspondence: abdannekaso@gmail.com; alemayehu.hailu@uib.no ${ }^{1}$ School of Public Health, Dilla University, Dilla, Ethiopia

${ }^{5}$ Bergen Centre for Ethics and Priority Setting, Department of Global Public Health and Primary Care, University of Bergen, Bergen, Norway Full list of author information is available at the end of the article
}

20, 2021), more than 140 million cases and over 3 million deaths have been globally attributed to Covid-19 [1]. In Ethiopia, the first cases of Covid-19 were reported on March 13, 2020. An Ethiopian Ministry of Health report states that more than 240,000 cases and 3,370 deaths have been reported [1]. The pandemic is causing a broad range of health, social and economic crises at a macro and micro level [2].

Covid-19's wide spectrum of symptoms ranges from mild manifestations to severe disease and death, and original author(s) and the source, provide a link to the Creative Commons licence, and indicate if changes were made. The images or other third party material in this article are included in the article's Creative Commons licence, unless indicated otherwise in a credit line to the material. If material is not included in the article's Creative Commons licence and your intended use is not permitted by statutory regulation or exceeds the permitted use, you will need to obtain permission directly from the copyright holder. To view a copy of this licence, visit http://creativecommons.org/licenses/by/4.0/. The Creative Commons Public Domain Dedication waiver (http://creativeco mmons.org/publicdomain/zero/1.0/) applies to the data made available in this article, unless otherwise stated in a credit line to the data. 


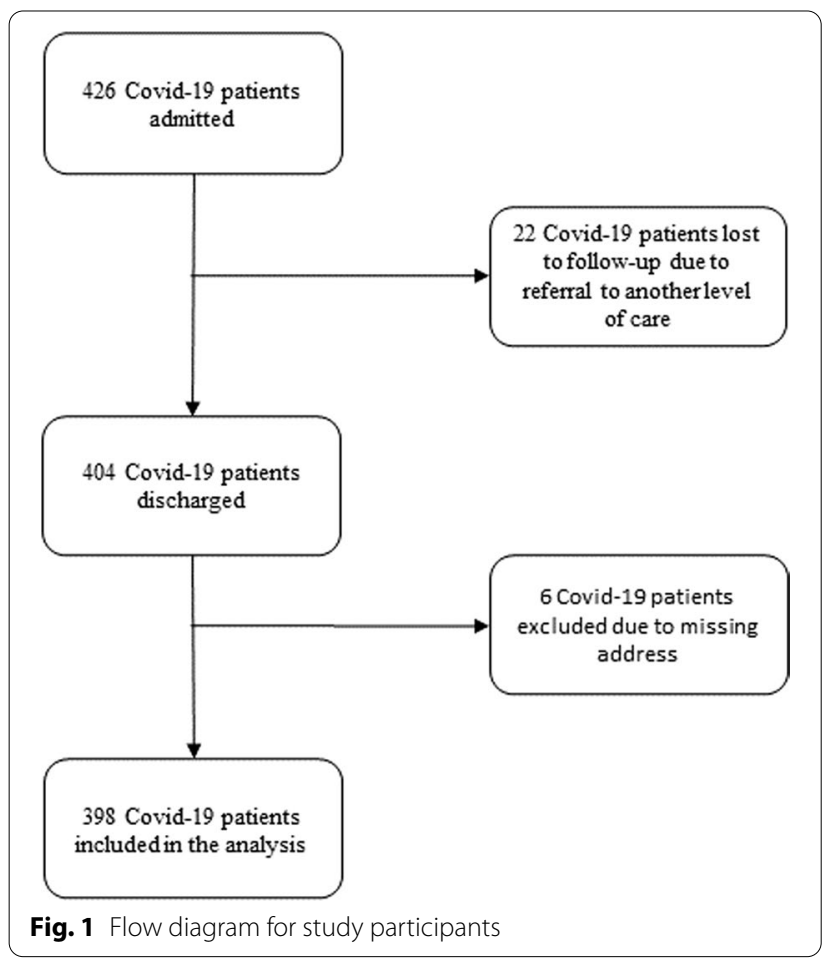

some people may have the disease without developing symptoms. The most common symptoms are upper respiratory tract conditions (sore throat, cold symptoms, mild cough), muscle pain and generally feeling unwell. Stomach pains and diarrhoea may occur in some cases, and the loss of the senses of taste and smell is also reported. Some patients may develop pneumonia with severe breathing difficulties, cough and fever and may need to be admitted to intensive care treatment units. Examination of the lungs usually finds changes consistent with viral pneumonia. Death is common among older people, particularly among the elderly with underlying diseases, but death can also occur among people without known risk factors $[3,4]$.

Health-related quality of life (HRQOL), an essential health care indicator for any disease type [5], measures patients' overall wellbeing in physical, mental and emotional aspects at a specific time. It can be used in evaluating the severity of a disease, treatment outcomes, patient satisfaction with care, quality of services, overall patient wellbeing and the cost-utility of interventions targeting the disease [5-8]. As Covid-19 is a new disease, however, little is known about its impact on HRQOL. In Italy, a retrospective analysis of HRQOL using SF-36 and involving 673 cases one month after discharge from San Salvatore Hospital in Pesaro found that Covid-19 caused a substantial reduction in patients' physical and mental health conditions. That study indicates that physical and emotional roles, vitality and social functioning were highly affected dimensions [9]. A retrospective study in China indicates that Covid-19 has a substantial impact on the physical and psychological dimensions of HRQOL [10]. Another multicentre follow-up study from China indicates that Covid-19 has a substantial effect on HRQOL, with some impacts persisting more than three months after discharge [11].

An HRQOL study using EQ-5D on a multi-ethnic Asian population in Singapore among Covid-19 and cardiovascular comorbid patients indicates that the mental health dimension of patient wellbeing was the most affected area [12]. An HRQOL study from Iran using the EQ-5D reports a significantly low HRQOL score among Covid-19 patients (0.6125) and indicates that socioeconomic factors (i.e., gender, age, educational status, employment status) and comorbidity status (i.e., having diabetes or cardiovascular disease) were significant predictors of HRQOL score [13].

Covid-19's impact on HRQOL varies from country to country due to socioeconomic factors, the treatment modalities offered (and their outcomes) and variations in the disease's severity and epidemiology [6]. However, although local evidence of the impact of Covid-19 on HRQOL is essential to inform national and regional Covid-19 treatment protocol designs, the disease's impact on HRQOL in the Ethiopian or African context was unknown. Therefore, this study assessed the impact of Covid-19 and associated factors on HRQOL using primary data from confirmed cases in a Covid-19 treatment centre in South Central Ethiopia.

\section{Methods}

\section{Study setting, design and population}

This study employed a facility-based, cross-sectional study design. We conducted this study in the Arsi Zone at the Bokoji Hospital Covid-19 treatment centre, one of the largest Covid-19 treatment centres in South Central Ethiopia, which provides services for people from 28 districts and two town administrations.

The sample size was determined using single population formula with assumption type I error of 0.05 , confidence interval 95\%, proportion of good HRQOL $(50 \%)$, and non-response $10 \%$. The final calculated sample size was 422 , and since the patients discharged and fulfilled the criteria were below this, all Covid-19 patients discharged from treatment were recruited for the study. The study population was all Covid-19 patients discharged from the treatment centre from July 1, 2020 through March 20, 2021. All Covid-19 patients discharged from the treatment centre after being cured or with consent for home-based care were 
included. Excluding all the Covid-19 patients referred to other treatment centre hospitals, incomplete medical records or deceased, 398 confirmed Covid-19 cases were included in the analysis (Fig. 1).

\section{Data collection and tools}

To measure the HRQOL of Covid-19 patients, we employed the visual analogue scale (VAS) alongside the EQ-5D-3L questionnaire, which is the most common instrument for assessing HRQOL. The EQ-5D-3L includes five dimensions (mobility, self-care, usual activities, pain/discomfort, anxiety/depression), each with three levels to define possible health states (no problems, some problems, inability to/extreme problems). The VAS is a vertical graduated line $(0-100)$ that indicates the overall health status of the respondent, 0 being the worst imaginable health state and 100 being the best imaginable. Four healthcare professionals collected the data after a two-day training on data collection procedures and the tools. Data collection was conducted using a face-toface interview. Additionally, information on sociodemographic and clinical characteristics was extracted from patients' medical records. The first author (AK) supervised the data collection.

\section{Study variables and operational definitions}

The health state utility (HSU) was the dependent variable. In contrast, sociodemographic variables, like age, sex, marital status, residence, and clinical variables like general health status during admission, chronic illnesses, dexamethasone treatment, internasal oxygen use and the average length of stay were the independent variables. Patients general health status were defined as asymptomatic, mild, moderate, severe or critically ill, according to the WHO as well as Ethiopian national diagnosis and treatment protocol. 'Asymptomatic infections' were defined as the absence of clinical signs and symptoms with a positive nucleic acid test, whereas 'Mild Covid19 disease' was defined as the presence of mild clinical signs and symptoms without respiratory distress and the absence of imaging manifestations of pneumonia. 'Moderate disease' was defined as the presence of clinical signs of pneumonia (fever, cough, dyspnoea, and fast breathing) but without symptoms of severe pneumonia, including $\mathrm{SpO} 2 \geq 90 \%$ on room air. Severe disease was defined as the presence of at least one of the three conditions: respiratory distress, a respiratory rate $\geq$ of 30 beats/min; oxygen saturation in resting-state $\leq 90 \%$; or an arterial blood oxygen partial pressure/oxygen concentration $\leq 200 \mathrm{mmHg}$. Critically ill was defined as respiratory failure requiring mechanical ventilation, shock or combined organ failure requiring intensive care unit
Table 1 Demographic and clinical characteristics of Covid-19 patients admitted to a treatment centre in the Arsi Zone, 20202021

\begin{tabular}{|c|c|}
\hline Demographic and clinical characteristics & Frequency (\%) \\
\hline \multicolumn{2}{|l|}{ Sex } \\
\hline Female & $159(40.0)$ \\
\hline Male & $239(60.0)$ \\
\hline \multicolumn{2}{|l|}{ Age (mean = 41.5 (SD: 18.8) } \\
\hline $0-24$ years & $83(20.9)$ \\
\hline $25-34$ & $102(25.6)$ \\
\hline $35-44$ & $52(13.1)$ \\
\hline $45-54$ & $46(11.6)$ \\
\hline 55 years and above & $115(28.9)$ \\
\hline \multicolumn{2}{|l|}{ Residence } \\
\hline Rural & $156(39.0)$ \\
\hline Urban & $242(61.0)$ \\
\hline \multicolumn{2}{|l|}{ Health status on admission } \\
\hline Asymptomatic & $95(23.9)$ \\
\hline Mild & $93(23.4)$ \\
\hline Moderate & $80(20.0)$ \\
\hline Severe & $130(32.7)$ \\
\hline \multicolumn{2}{|l|}{ Comorbidity } \\
\hline Yes & $179(45.0)$ \\
\hline No & $219(55.0)$ \\
\hline \multicolumn{2}{|l|}{ Type of comorbidity } \\
\hline Diabetes mellitus & $68(17.1)$ \\
\hline Hypertension & $41(10.3)$ \\
\hline Asthma & $33(8.3)$ \\
\hline Chronic pulmonary disease & $30(7.5)$ \\
\hline Chronic cardiac diseases & $23(5.8)$ \\
\hline Malignancy & $11(2.8)$ \\
\hline Chronic kidney disease & $7(1.8)$ \\
\hline HIV/AIDS & $6(1.5)$ \\
\hline \multicolumn{2}{|l|}{ Types of antibiotic administered } \\
\hline Azithromycin only & $148(37.2)$ \\
\hline Azithromycin + ceftriaxone & $131(32.9)$ \\
\hline Azithromycin + vancomycin + ceftazidime & $50(12.6)$ \\
\hline Azithromycin + ceftriaxone + metronidazole & $30(7.5)$ \\
\hline Azithromycin + ceftriaxone + vancomycin & $24(6.0)$ \\
\hline Azithromycin + ceftriaxone + amoxicillin & $13(3.3)$ \\
\hline Azithromycin + ceftriaxone + ceftazidime & $2(0.5)$ \\
\hline \multicolumn{2}{|l|}{ Dexamethasone used } \\
\hline Yes & $116(29.1)$ \\
\hline No & $282(70.9)$ \\
\hline \multicolumn{2}{|l|}{ Intranasal oxygen used } \\
\hline Yes & $162(59.3)$ \\
\hline No & $236(40.7)$ \\
\hline \multicolumn{2}{|l|}{ Length of hospital stay (mean =14.3 SD:4.8) } \\
\hline $1-7$ days & $12(3.0)$ \\
\hline $8-14$ days & $248(61.8)$ \\
\hline $15-21$ days & $113(28.4)$ \\
\hline $22-28$ days & $13(3.3)$ \\
\hline More than 28 days & $14(5.5)$ \\
\hline
\end{tabular}


(ICU) monitoring and treatment [14, 15]. Health status at discharge was cured, transferred or discharged with consent. Cured was defined as the Covid-19 patients discharged after two times negative laboratory finding was confirmed. Discharged with consent was defined as Covid-19 patients discharged with consent after their one laboratory result was positive after at least 14 days stay in the treatment centre. Similarly, transfer was defined as Covid-19 patients transferred to other treatment centres for more management of Covid-19 or complications due to underlying diseases.

\section{Data analysis}

The HRQOL results measured by the EQ-5D-3L tool were converted to a health state utility (HSU) using the Zimbabwe tariff value set, while the VAS scores were taken directly as another HSU (HSU-VAS) [16]. Both the HUI from the EQ-5D-3L and the overall HSU-VAS from the VAS score were analysed as a continuous variables. We used frequencies and percentages to summarise the sociodemographic and clinical characteristics of the participants and summarised the HUIs by median with interquartile range (IQR) and mean with a standard deviation (SD). We compared the average HUI and HSU-VAS across various groups of sociodemographic and clinical characteristics using the Mann-Whitney $U$ test or the Kruskal-Wallis test. We examined the data for normality, multicollinearity, and heteroscedasticity statistical assumptions. To assess the factors associated with HSU simultaneously, we employed a multiple linear regression. We calculated coefficient $(\beta)$ and $95 \%$ confidence intervals (CIs). A P-value of less than 0.05 was considered statistically significant. We used STATA version 15 for data analysis.

\section{Ethical approval}

This study was approved by the Ethical Review Board of Arsi University College of Health Sciences. Informed consent was obtained from all the participants. We used the STROBE cross-sectional checklist when writing our report [17].

\section{Results}

A total of 398 confirmed Covid-19 cases were included in the study. The average length of hospital stay was 14.3 days (SD: 4.78). The majority of the Covid-19 cases were male $(60 \%)$, older than 55 years $(28.9 \%)$ (Maximum $=95$ years old) and residents of urban areas $(61 \%)$. Regarding general health status on admission, $32.7 \%$ were severely ill, $20 \%$ had a moderate symptom, $23.4 \%$ had mild symptoms, and $23.9 \%$ were asymptomatic. Fortyfive percent of the cases had some comorbidity, with diabetes mellitus (17.1\%), hypertension (10.3\%) and asthma (8.3\%) being the top three comorbidities. Regarding the antibiotic treatment regimen, $37.2 \%$ were treated with azithromycin, while $32.9 \%$ received a combination of azithromycin and ceftriaxone. In addition, about onethird $(29.1 \%)$ were treated with dexamethasone. Furthermore, nearly two-thirds (59.3\%) received intranasal oxygen supplementation (Table 1).

The overall mean HSU of the EQ-5D index score was 0.688 (SD: 0.285) (Table 2). The overall mean HSU of the VAS score was 0.690 (SD: 0.129) (Table 3). There was significant variation in the mean HSU score across age groups $(p<0.001)$. The mean EQ-5D index score among those older than 55 years was 0.567 , while it was 0.783 among those younger than 25 years. In general, the mean EQ-5D index scores were significantly lower for respondents with comorbidity (0.574) than for those without comorbidity $(0.777) \quad(p<0.001)$ (Table 3$)$. The EQ-5D index score was significantly lower among those with hypertension, chronic cardiac diseases, chronic pulmonary disease, asthma, chronic kidney disease and diabetes mellitus than among those who did not have those comorbidities. Those who received dexamethasone and supplemental intranasal oxygen had significantly lower EQ-5D index scores than those who did not receive them $(p<0.001)$, but there was no difference in the EQ-5D index score across gender and place of residence (urban vs. rural). The mean HSU for VAS score was 0.629 among those older than 55 years, whereas it was 0.732 among those younger than 25 years. Moreover, the mean VAS scores were significantly lower for respondents on intranasal oxygen (0.604) than their counterparts (0.749) $(p<0.001)$. Respondents who received dexamethasone treatment $\quad(p<0.001)$, with hypertension $(p<0.002)$, chronic cardiac disease $(p<0.005)$, chronic pulmonary disease $(p<0.001)$, diabetic mellitus $(p<0.001)$ and asthma $(p<0.001)$ were associated with lower VAS score (Table 3).

The multiple linear regression analysis results are presented in Table 4. The patient's age, having asthma as comorbidity, and general health status during admission were significantly associated with low HSU values. On the other hand, those who were treated with dexamethasone had significantly higher HSU values $(\mathrm{P}$-value $<0.05)$ (Table 4). 
Table 2 Comparison of the HSU values of the EQ-5D-3L tool across the demographic and clinical characteristics of Covid-19 patients admitted to a treatment centre in the Arsi Zone, 2020-2021

\begin{tabular}{|c|c|c|c|c|c|c|}
\hline \multirow[t]{2}{*}{ Variable } & \multicolumn{6}{|c|}{ Health utility value (EQ-5D-3L) } \\
\hline & Median & IQR (P25, P75) & & Mean & SD & $p$ value \\
\hline \multicolumn{7}{|l|}{ Sex } \\
\hline Female & 0.787 & 0.596 & 0.833 & 0.684 & 0.302 & 0.818 \\
\hline Male & 0.787 & 0.596 & 0.854 & 0.689 & 0.274 & \\
\hline \multicolumn{7}{|l|}{ Age } \\
\hline $0-24$ & 0.787 & 0.596 & 1.000 & 0.783 & 0.199 & $<0.001$ \\
\hline $25-34$ & 0.787 & 0.596 & 1.000 & 0.778 & 0.213 & \\
\hline $35-44$ & 0.787 & 0.596 & 0.787 & 0.649 & 0.328 & \\
\hline $45-54$ & 0.691 & 0.596 & 0.854 & 0.653 & 0.213 & \\
\hline $55+$ & 0.596 & 0.596 & 0.787 & 0.567 & 0.314 & \\
\hline \multicolumn{7}{|l|}{ Residence } \\
\hline Rural & 0.787 & 0.596 & 0.854 & 0.692 & 0.282 & 0.967 \\
\hline Urban & 0.787 & 0.596 & 0.833 & 0.685 & 0.288 & \\
\hline \multicolumn{7}{|l|}{ Comorbidity } \\
\hline No & 0.787 & 0.596 & 1.000 & 0.777 & 0.257 & $<0.001$ \\
\hline Yes & 0.596 & 0.596 & 0.787 & 0.574 & 0.279 & \\
\hline \multicolumn{7}{|l|}{ Hypertension } \\
\hline No & 0.787 & 0.596 & 0.854 & 0.699 & 0.285 & 0.001 \\
\hline Yes & 0.596 & 0.596 & 0.787 & 0.580 & 0.267 & \\
\hline \multicolumn{7}{|c|}{ Chronic cardiac diseases } \\
\hline No & 0.787 & 0.596 & 0.854 & 0.697 & 0.280 & 0.004 \\
\hline Yes & 0.596 & 0.596 & 0.787 & 0.518 & 0.320 & \\
\hline \multicolumn{7}{|c|}{ Chronic pulmonary disease } \\
\hline No & 0.787 & 0.596 & 0.854 & 0.703 & 0.277 & $<0.001$ \\
\hline Yes & 0.596 & 0.596 & 0.596 & 0.499 & 0.311 & \\
\hline \multicolumn{7}{|l|}{ Asthma } \\
\hline No & 0.787 & 0.596 & 0.854 & 0.706 & 0.252 & $<0.001$ \\
\hline Yes & 0.596 & 0.469 & 0.596 & 0.487 & 0.329 & \\
\hline \multicolumn{7}{|c|}{ Chronic kidney disease } \\
\hline No & 0.787 & 0.596 & 0.854 & 0.690 & 0.286 & 0.029 \\
\hline Yes & 0.596 & 0.361 & 0.596 & 0.535 & 0.186 & \\
\hline \multicolumn{7}{|c|}{ Diabetes mellitus } \\
\hline No & 0.787 & 0.596 & 1.000 & 0.711 & 0.281 & $<0.001$ \\
\hline Yes & 0.596 & 0.596 & 0.787 & 0.575 & 0.280 & \\
\hline \multicolumn{7}{|l|}{ Malignancy } \\
\hline No & 0.787 & 0.596 & 0.854 & 0.687 & 0.288 & 0.859 \\
\hline Yes & 0.787 & 0.596 & 0.833 & 0.708 & 0.147 & \\
\hline \multicolumn{7}{|l|}{ HIV/AIDS } \\
\hline No & 0.787 & 0.596 & 0.843 & 0.688 & 0.285 & 0.354 \\
\hline Yes & 0.692 & 0.596 & 0.787 & 0.607 & 0.270 & \\
\hline \multicolumn{7}{|c|}{ Dexamethasone used } \\
\hline No & 0.787 & 0.596 & 1.000 & 0.735 & 0.280 & $<0.001$ \\
\hline Yes & 0.596 & 0.596 & 0.787 & 0.571 & 0.262 & \\
\hline \multicolumn{7}{|c|}{ Intranasal oxygen used } \\
\hline No & 0.787 & 0.787 & 1.000 & 0.816 & 0.180 & $<0.001$ \\
\hline Yes & 0.596 & 0.596 & 0.596 & 0.500 & 0.305 & \\
\hline \multicolumn{7}{|c|}{ Length of hospital stay } \\
\hline 1-7 days & 0.691 & 0.596 & 0.866 & 0.718 & 0.227 & 0.002 \\
\hline 8-14 days & 0.787 & 0.596 & 1.000 & 0.719 & 0.283 & \\
\hline
\end{tabular}


Table 2 (continued)

\begin{tabular}{|c|c|c|c|c|c|c|}
\hline \multirow[t]{2}{*}{ Variable } & \multicolumn{6}{|c|}{ Health utility value (EQ-5D-3L) } \\
\hline & Median & IQR (P25, P75) & & Mean & SD & $p$ value \\
\hline 15-21 days & 0.596 & 0.596 & 0.787 & 0.622 & 0.297 & \\
\hline $22-28$ days & 0.596 & 0.596 & 0.787 & 0.715 & 0.197 & \\
\hline More than 28 days & 0.596 & 0.469 & 0.787 & 0.604 & 0.241 & \\
\hline Overall & 0.787 & 0.596 & 0.833 & 0.688 & 0.285 & \\
\hline
\end{tabular}

$\mathrm{SD}=$ standard deviation; $\mathrm{IQR}=$ interquartile range; $\mathrm{P}$-values are from the Mann-Whitney $\mathrm{U}$ test or Kruskal-Wallis test

\section{Discussion}

Covid-19 has caused significant psychological and physiological stress to patients and their families worldwide. This study examined the HRQOL of Covid-19 patients using the EQ-5D-3L and VAS tools. The overall mean VAS score was 0.690 (median $=0.700$ ) in our study. This was similar with study from Egypt (72.2) [20],Peru (76) [21],Spain (66.36) [13], China (85.52) [20] and Addis Ababa, Ethiopia (69.44) [22]. Moreover, the mean EQ-5D index score among Covid-19 patients on discharge was $0.688(\mathrm{SD}=0.285)$.In general, these findings are in line with those of a study in Iran that reports an EQ-5D index score of 0.612 [13] and a Belgian study with an EQ-5D index score of 0.620 [18], but our findings are substantially lower than those of studies from Norway (EQ-5D index score: 0.820) [19], China (EQ-5D index score: 0.949 ) and Hong Kong (EQ-5D index score: 0.897) $[20,21]$. Variations in the HRQOL evaluation method employed (i.e., health utility tariff, tools, scale, study participant sampling) may also, to some extent, contribute to the discrepancy. The studies in China, Iran, Argentina, Belgium and Norway employed the EQ-5D-5L instrument, while our study employed the EQ-5D-3L. Moreover, the variation in age distribution may be a driver of variation in HRQOL across countries, and the population in our study was relatively younger (mean age $=40$ ) than in other places.

In our study, respondents age 55 and above years old had a significantly lower HRQOL than younger people $(0.567$ vs 0.783$)$. This is similar with finding from, Iran( 0.554 vs 0.618 ) [13], China (0.963 vs 0.889 ) [20], and South Africa (0.655 vs 0.501) [22]. Moreover, in regression analysis, age was also significantly associated with health utility status. This finding is in line with a find from Argentina study [23]. According to the Argentian study, those older than 50 were 5.6 times more likely to have poor HRQOL than their counterparts. This finding can be explained by increased mental stress, comorbidity and debilitation in the physical condition of older people [24]. In contrast, those middle-aged males ( $26-35$ years) patients were five times more at risk of having poor
HRQOL in Saudi Arabia compared with older counterparts (55-65 years) [25].

According to our study, comorbidity, especially asthma (Table 4), is significantly associated with lower health utility scores (Table 2). This similar with studies from Vietnam [26], Palestine [27], Peru [28], India [29] and Addis Ababa, Ethiopia [30]. The mean VASscores were significantly lower for respondents with comorbidity (62) than for those without it $(75)(p<0.001)$. In general, comorbidities (such as hypertension, chronic cardiac diseases, chronic pulmonary disease, asthma, chronic kidney disease and diabetes mellitus) were significantly associated with low HSU VAS scores. Studies from Vietnam (70.8 vs 63.3) [31], China (97.9 Vs 82.8) [20] and Palestine (80 vs 70) [27] revealed that individuals with chronic diseases have a lower HRQOL than those without comorbid disease, perhaps because those with comorbidities develop anxiety or depression in response to misinformation disseminated about the impact of the virus in these communities [25,32].

We found that Covid-19 patients who received dexamethasone and intranasal oxygen supplementation had lower EQ-5D index scores than those who did not receive them $(p<0.001)$, perhaps because those who needed those treatments had a severe form of the illness. Furthermore, those with a length of stay (LOS) of more than 15 days in hospital had lower EQ-5D index scores than their counterparts. Studies from China, Spain and Argentina also revealed that increased LOS is associated with poor HRQOL [10,33-35]. This poor HRQOL might be due to confinement to one place, increasing anxiety and reducing the HRQOL in general.

This study represents the first comprehensive analysis of the HRQOL of Covid-19 patients in the Ethiopian setting to the best of our knowledge. We conducted the study in a setting that accommodated patients from 28 districts. However, our study has some limitations. First, because the study collected HRQOL data based on patient preferences, the patients might over or underestimated their health status during the interview. Second, we have no HRQOL estimate for 22 patients who lost to follow-up due to referral to another level of 
Table 3 Comparison of the HSU values of the VAS across the demographic and clinical characteristics of Covid-19 patients admitted to a treatment centre in the Arsi Zone, 2020-2021

\begin{tabular}{|c|c|c|c|c|c|c|}
\hline \multirow[t]{2}{*}{ Variable } & \multicolumn{6}{|c|}{ Health utility value (VAS) } \\
\hline & \multirow[t]{2}{*}{ Median } & \multicolumn{2}{|c|}{ IQR (P25, P75) } & \multirow[t]{2}{*}{ Mean } & \multirow[t]{2}{*}{ SD } & \multirow[t]{2}{*}{$p$ value } \\
\hline \multicolumn{3}{|l|}{ Sex } & & & & \\
\hline Female & 0.700 & 0.600 & 0.800 & 0.689 & 0.134 & 0.961 \\
\hline Male & 0.700 & 0.600 & 0.800 & 0.692 & 0.127 & \\
\hline \multicolumn{7}{|l|}{ Age } \\
\hline $0-24$ & 0.725 & 0.610 & 0.860 & 0.732 & 0.126 & $<0.001$ \\
\hline $25-34$ & 0.750 & 0.650 & 0.840 & 0.734 & 0.121 & \\
\hline $35-44$ & 0.700 & 0.580 & 0.780 & 0.686 & 0.126 & \\
\hline $45-54$ & 0.680 & 0.600 & 0.780 & 0.678 & 0.123 & \\
\hline $55+$ & 0.620 & 0.560 & 0.710 & 0.629 & 0.118 & \\
\hline \multicolumn{7}{|l|}{ Residence } \\
\hline Rural & 0.700 & 0.600 & 0.810 & 0.695 & 0.132 & 0.927 \\
\hline Urban & 0.700 & 0.600 & 0.790 & 0.688 & 0.128 & \\
\hline \multicolumn{7}{|l|}{ Comorbidity } \\
\hline No & 0.750 & 0.640 & 0.850 & 0.738 & 0.129 & $<0.001$ \\
\hline Yes & 0.620 & 0.570 & 0.710 & 0.632 & 0.103 & \\
\hline \multicolumn{7}{|l|}{ Hypertension } \\
\hline No & 0.700 & 0.600 & 0.800 & 0.697 & 0.131 & 0.002 \\
\hline Yes & 0.610 & 0.580 & 0.700 & 0.634 & 0.096 & \\
\hline \multicolumn{7}{|c|}{ Chronic cardiac diseases } \\
\hline No & 0.700 & 0.600 & 0.800 & 0.695 & 0.129 & 0.005 \\
\hline Yes & 0.630 & 0.570 & 0.700 & 0.613 & 0.102 & \\
\hline \multicolumn{7}{|c|}{ Chronic pulmonary disease } \\
\hline No & 0.700 & 0.600 & 0.800 & 0.697 & 0.130 & $<0.001$ \\
\hline Yes & 0.605 & 0.570 & 0.660 & 0.606 & 0.081 & \\
\hline \multicolumn{7}{|l|}{ Asthma } \\
\hline No & 0.700 & 0.600 & 0.800 & 0.699 & 0.129 & $<0.001$ \\
\hline Yes & 0.590 & 0.560 & 0.640 & 0.601 & 0.096 & \\
\hline \multicolumn{7}{|c|}{ Chronic kidney disease } \\
\hline No & 0.700 & 0.600 & 0.800 & 0.692 & 0.129 & 0.081 \\
\hline Yes & 0.630 & 0.550 & 0.660 & 0.607 & 0.094 & \\
\hline \multicolumn{7}{|c|}{ Diabetes mellitus } \\
\hline No & 0.705 & 0.600 & 0.820 & 0.705 & 0.129 & $<0.001$ \\
\hline Yes & 0.700 & 0.570 & 0.700 & 0.622 & 0.109 & \\
\hline \multicolumn{7}{|l|}{ Malignancy } \\
\hline No & 0.700 & 0.600 & 0.800 & 0.691 & 0.130 & 0.782 \\
\hline Yes & 0.710 & 0.600 & 0.780 & 0.675 & 0.117 & \\
\hline \multicolumn{7}{|l|}{ HIV/AIDS } \\
\hline No & 0.700 & 0.600 & 0.800 & 0.691 & 0.129 & 0.531 \\
\hline Yes & 0.665 & 0.590 & 0.750 & 0.653 & 0.112 & \\
\hline \multicolumn{7}{|c|}{ Dexamethasone used } \\
\hline No & 0.730 & 0.610 & 0.848 & 0.718 & 0.131 & $<0.001$ \\
\hline Yes & 0.600 & 0.570 & 0.700 & 0.625 & 0.097 & \\
\hline Intranasal oxyg & & & & & & \\
\hline No & 0.750 & 0.695 & 0.850 & 0.749 & 0.116 & $<0.001$ \\
\hline Yes & 0.600 & 0.560 & 0.660 & 0.604 & 0.096 & \\
\hline Length of hosp & & & & & & \\
\hline $1-7$ days & 0.690 & 0.610 & 0.820 & 0.703 & 0.133 & 0.004 \\
\hline 8-14 days & 0.720 & 0.600 & 0.820 & 0.709 & 0.229 & \\
\hline $15-21$ days & 0.640 & 0.590 & 0.730 & 0.657 & 0.122 & \\
\hline
\end{tabular}


Table 3 (continued)

\begin{tabular}{|c|c|c|c|c|c|c|}
\hline \multirow[t]{2}{*}{ Variable } & \multicolumn{6}{|c|}{ Health utility value (VAS) } \\
\hline & Median & IQR (P & & Mean & SD & $p$ value \\
\hline $22-28$ days & 0.640 & 0.600 & 0.750 & 0.687 & 0.127 & \\
\hline More than 28 days & 0.615 & 0.530 & 0.730 & 0.629 & 0.131 & \\
\hline Overall & 0.700 & 0.600 & 0.800 & 0.690 & 0.129 & \\
\hline
\end{tabular}

$\mathrm{SD}=$ standard deviation; $\mathrm{IQR}=$ interquartile range; $\mathrm{P}$-values are from the Mann-Whitney $\mathrm{U}$ test or Kruskal-Wallis test

Table 4 Multiple linear regression analysis for factors associated with HSU values of Covid-19 patients admitted to a treatment centre in the Arsi Zone, 2020-2021

\begin{tabular}{|c|c|c|c|c|c|c|c|c|}
\hline \multirow[t]{2}{*}{ Variables } & \multicolumn{4}{|c|}{ HSU values of the EQ-5D (Adjusted R²: 45\%) } & \multicolumn{4}{|c|}{ HSU values of the VAS (Adjusted $\mathrm{R}^{2}: 55 \%$ ) } \\
\hline & Coef & $p$ value & {$[95 \% \mathrm{Cl}]$} & & Coef & $p$ value & {$[95 \% \mathrm{Cl}]$} & \\
\hline Sex (Ref: Female) & 0.024 & 0.276 & -0.019 & 0.068 & 0.013 & 0.155 & -0.005 & 0.031 \\
\hline Age (in year) & -0.001 & 0.048 & -0.002 & 0.000 & 0.000 & 0.030 & -0.001 & 0.000 \\
\hline Residence (Ref: Rural) & -0.003 & 0.905 & -0.047 & 0.042 & -0.004 & 0.695 & -0.022 & 0.014 \\
\hline Hypertension (Ref: No) & -0.017 & 0.652 & -0.089 & 0.056 & -0.015 & 0.326 & -0.044 & 0.015 \\
\hline Chronic cardiac diseases (Ref: No) & -0.032 & 0.512 & -0.129 & 0.065 & -0.018 & 0.371 & -0.058 & 0.022 \\
\hline Chronic pulmonary disease (Ref: No) & -0.018 & 0.678 & -0.101 & 0.066 & -0.007 & 0.689 & -0.041 & 0.027 \\
\hline Asthma (Ref: No) & -0.091 & 0.024 & -0.169 & -0.012 & -0.036 & 0.029 & -0.068 & -0.004 \\
\hline Chronic kidney disease (Ref: No) & 0.022 & 0.788 & -0.140 & 0.185 & -0.003 & 0.933 & -0.069 & 0.064 \\
\hline Diabetes mellitus (Ref: No) & -0.008 & 0.791 & -0.069 & 0.053 & -0.017 & 0.192 & -0.041 & 0.008 \\
\hline Malignance (Ref: No) & -0.009 & 0.887 & -0.140 & 0.121 & -0.038 & 0.158 & -0.092 & 0.015 \\
\hline AIDS HIV (Ref: No) & 0.039 & 0.664 & -0.137 & 0.215 & 0.030 & 0.409 & -0.042 & 0.103 \\
\hline Dexamethasone use (Ref: No) & 0.089 & 0.002 & 0.033 & 0.145 & 0.026 & 0.026 & 0.003 & 0.049 \\
\hline Intra nasal oxygen use (Ref: No) & -0.042 & 0.251 & -0.114 & 0.030 & 0.012 & 0.421 & -0.017 & 0.042 \\
\hline \multicolumn{9}{|l|}{ Health status on admission } \\
\hline Mild (Ref: No symptom) & -0.093 & 0.004 & -0.156 & -0.031 & -0.064 & 0.000 & -0.089 & -0.038 \\
\hline Moderate (Ref: No symptom) & -0.269 & 0.000 & -0.341 & -0.197 & -0.171 & 0.000 & -0.200 & -0.142 \\
\hline Severe/ critical (Ref: No symptom) & -0.445 & 0.000 & -0.537 & -0.353 & -0.243 & 0.000 & -0.281 & -0.206 \\
\hline Length of stay (in days) & -0.001 & 0.767 & -0.005 & 0.004 & -0.001 & 0.237 & -0.003 & 0.001 \\
\hline _cons & 0.955 & 0.000 & 0.870 & 1.039 & 0.847 & 0.000 & 0.812 & 0.881 \\
\hline
\end{tabular}

Coef: Coefficient; Cl: Confidence Interval; SE: Standard Error; Ref: Reference category

care. In addition, this study used the Zimbabwe tariff due to the lack of an Ethiopian tariff, and this limitation could impact the estimation of the real Ethiopian HRQOL against the disease, as there are many differences between the two countries. Moreover, due to the study's cross-sectional design, we could not compare the HRQOL of patients before the Covid-19 infection.

\section{Conclusion}

In conclusion, the Covid-19 disease substantially impaired the HRQOL of patients in Ethiopia. Elderly patients and Covid-19 patients with comorbidity had notably low HRQOLs. Therefore, close clinical followup and psychological treatment should be encouraged for these groups. Moreover, the health utility values from this study can be used to evaluate quality adjusted life years for future cost-effectiveness analyses of prevention and treatment interventions against Covid-19.

\section{Abbreviations}

EQ-5D-3L: Euro Qal-5 Dimension-3 Level; HRQOL: Health-related quality of life; HIV: Human immune virus; HUI: Health utility index; HSU: Health state utility; LOS: Length of stay; ICU: Intensive care unit; SD: Standard deviation; SF-36: Standard format-36; VAS: Visual analogue scale; WHO: World Health Organization.

\section{Acknowledgements}

We wish to express our deepest gratitude to the Bokoji Hospital administration and staff, particularly for their data collection input. Our appreciation also goes to Mr Mengesha Moges, Dr Temam Bonso, Mr Feyisa Dabal, and Mr Abdisa Kasu for sincere support during the data collection. AH was supported by University of Bergen, Trond Mohn Foundation and NORAD through BCEPS. 


\section{Authors' contributions}

AK, GA, TK, ZH, AH and HA designed and worked on the study protocols. GA, TK, ZH and AK prepared a data collection tool and trained the data collectors. AK supervised the data collection process. AK, GA and HA analysed the data, interpreted the results and wrote the first draft manuscript. All authors read and approved the final manuscript.

\section{Funding}

Not applicable.

\section{Availability of data and materials}

The data sets used or analysed in this study are available from the corresponding author upon reasonable request.

\section{Declarations}

\section{Consent for publication}

Not applicable.

\section{Competing interests}

The authors declare that they have no competing interests.

\section{Author details}

${ }^{1}$ School of Public Health, Dilla University, Dilla, Ethiopia. ${ }^{2}$ Department of Public Health, College of Health Science, Arsi University, Assela, Ethiopia. ${ }^{3}$ Department of Internal Medicine, College of Health Science, Arsi University, Assela, Ethiopia. ${ }^{4}$ Department of Surgery, College of Health Science, Arsi University, Assela, Ethiopia. ${ }^{5}$ Bergen Centre for Ethics and Priority Setting, Department of Global Public Health and Primary Care, University of Bergen, Bergen, Norway.

Received: 22 July 2021 Accepted: 30 November 2021

Published online: 20 December 2021

\section{References}

1. WHO Coronavirus (COVID-19) Dashboard [https://covid19.who.int/]

2. Josephson A, Kilic T, Michler JD. Socioeconomic impacts of COVID-19 in low-income countries. Nat Hum Behav. 2021;5:557-65.

3. Madahar P, Wunsch H, Jha P, Slutsky AS, Brodie D. Trends in COVID-19-related in-hospital mortality: lessons learned from nationwide samples. Lancet Respir Med. 2021;9:322-4.

4. Brehm TT, van der Meirschen M, Hennigs A, Roedl K, Jarczak D, Wichmann D, Frings D, Nierhaus A, Oqueka T, Fiedler W, et al. Comparison of clinical characteristics and disease outcome of COVID-19 and seasonal influenza. Sci Rep. 2021;11:5803.

5. Karimi M, Brazier J. Health, health-related quality of life, and quality of life: what is the difference? Pharmacoeconomics. 2016;34:645-9.

6. Aaronson N, Alonso J, Burnam A, Lohr KN, Patrick DL, Perrin E, Stein RE. Assessing health status and quality-of-life instruments: attributes and review criteria. Qual Life Res. 2002;11:193-205.

7. Kularatna S, Whitty JA, Johnson NW, Scuffham PA. Health state valuation in low- and middle-income countries: a systematic review of the literature. Value Health. 2013;16:1091-9.

8. Brazier J, Ratcliffe J, Saloman J, Tsuchiya A. Measuring and valuing health benefits for economic evaluation. Oxford: Oxford University Press; 2017.

9. Temperoni C, Grieco S, Pasquini Z, Canovari B, Polenta A, Gnudi U, Montalti R, Barchiesi F. Clinical characteristics, management and health related quality of life in young to middle age adults with COVID-19. BMC Infect Dis. 2021:21:134.

10. Chen KY, Li T, Gong FH, Zhang JS, Li XK. Predictors of health-related quality of life and influencing factors for COVID-19 patients, a follow-up at one month. Front Psychiatry. 2020;11:668.

11. Qu G, Zhen Q, Wang W, Fan S, Wu Q, Zhang C, Li B, Liu G, Yu Y, Li Y, et al. Health-related quality of life of COVID-19 patients after discharge: A multicenter follow-up study. J Clin Nurs. 2021;30:1742-50.

12. Silva GO, Andrade-Lima A, Germano-Soares AH, de Lima-Junior D, Rodrigues SLC, Ritti-Dias RM, Farah BQ. Factors Associated with Quality of Life in Patients with Systemic Arterial Hypertension. International Journal of Cardiovascular Sciences. 2020;2020(33):133-42.

13. Arab-Zozani M, Hashemi F, Safari H, Yousefi M, Ameri H. Health-related quality of life and its associated factors in COVID-19 patients. Osong Public Health Res Perspect. 2020;11:296-302.

14. WHO: Clinical management of COVID-19: interim guidance. 27 may 2020.

15. FMOH: National guideline for integration of Covid-19 and Essential Healthcare services. Addis Ababa, Ethiopia; 2021.

16. Jelsma J, Hansen K, De Weerdt W, De Cock P. P K: How do Zimbabweans value health states? Popul Health Metrics. 2003;1:11.

17. von Elm E, Altman DG, Egger M, Pocock SJ, Gotzsche PC, Vandenbroucke JP. The Strengthening the Reporting of Observational Studies in Epidemiology (STROBE) Statement: guidelines for reporting observational studies. Int J Surg. 2014;12(12):1495-9.

18. Meys R, Delbressine JM, Goertz YMJ, Vaes AW, Machado FVC, Van Herck M, Burtin C, Posthuma R, Spaetgens B, Franssen FME, et al. Generic and respiratory-specific quality of life in non-hospitalised patients with COVID-19. J Clin Med. 2020;9:3993.

19. Garratt AM, Ghanima W, Einvik G, Stavem K. Quality of life after COVID-19 without hospitalisation: good overall, but reduced in some dimensions. J Infect. 2021;82:227-30.

20. Ping WW, Zheng JZ, Niu XH, Guo CZ, Zhang JF, Yang H, Shi Y. Evaluation of health-related quality of life using EQ-5D in China during the COVID-19 pandemic. PLOS ONE. 2020;15:e0234850.

21. Wong EL-Y, Ho K-F, Wong SY-S, Cheung AW-L, Yau PS-Y, Dong D, Yeoh E-K. Views on workplace policies and its impact on health-related quality of life during coronavirus disease (COVID-19) pandemic: cross-sectional survey of employees. Int J Health Policy Manag. 2020;X:1-10.

22. Kastien-Hilka T, Rosenkranz B, Sinanovic E, Bennett B, Schwenkglenks S. Health-related quality of life in South African patients with pulmonary tuberculosis. PLOS ONE. 2017:12:10.

23. Busico M, Intile D, Sívori M, Irastorza N, Alvarez AL, Quintana J, Vazquez L, Plotnikow G, Villarejo F, Desmery P. Risk factors for worsened quality of life in patients on mechanical ventilation. A prospective multicenter study. Med Intensiva. 2016:40:422-30.

24. Asadollahi R, Saghafinia M, Nafissi N, Montazeri A, Asadollahi M, Khatami M. Anxiety, depression and health-related quality of life in those injured by landmines, Ilam, Islamic Republic of Iran. EMHJ. 2010;16:10.

25. Algahtani FD, Hassan SUN, Alsaif B, Zrieq R. Assessment of the quality of life during COVID-19 Pandemic: a cross-sectional survey from the Kingdom of Saudi Arabia. Int J Environ Res Public Health. 2021;18:10.

26. Ngo CQ, Phan PT, Vu GV, Pham QLT, Nguyen LH, Vu GT, Tran TT, Nguyen HLT. Effects of different comorbidities on health-related quality of life among respiratory patients in Vietnam. J Clin Med. 2019;8:10.

27. Hamdan A, Ghanim M, Mosleh R. COVID-19 confinement and related well being measurement using the EQ-5D questionnaire: a survey among the Palestinian population. Int J Clin Pract. 2021;75(10):e14621.

28. Figueroa-Quiñones J, I panaqué-Zapata M, Machay-Pak D, Rodríguez-Ruiz J. Quality of life and depressive symptoms among Peruvian university students 2 during the COVID-19 pandemic. Preprint. bioRxiv. https:// pesquisa.bvsalud.org/portal/resource/pt/ppbiorxiv-411330.

29. Suresh $\mathrm{H}$. Assessment of health-related quality of life using EQ-5D among residents of mysore during the coronavirus disease pandemic. Ann Commun Health. 2021;9:127-32.

30. Shimels T, Kassu RA, Bogale G, Bekele M, Getnet M, Getachew A, Shewamene $Z$, Abraha M. Health related quality of life of patients with chronic non-communicable diseases during the coronavirus pandemic in Ethiopia: a multi-facility study. 2020. Preprint. https://doi.org/10.21203/ rs.3.rs-108488/v1.

31. Nguyen HC, Nguyen MH, Do BN, Tran CQ, Nguyen TTP, Pham KM, Pham LV, Tran KV, Duong TT. People with suspected COVID-19 symptoms were more likely depressed and had lower health-related quality of life: the potential benefit of health literacy. J Clin Med. 2020;9:10.

32. Greco F, Altieri VM, Esperto F, Mirone V, Scarpa RM. Impact of COVID-19 pandemic on health-related quality of life in uro-oncologic patients: what should we wait for. Clin Genitourinary Cancer. 2020;19(2):e63-8.

33. Qi ML, Li P, Moyle W, Weeks B, Jones C. Physical activity, health-related quality of life, and stress among the chinese adult population during the COVID-19 pandemic. Int J Environ Res Public Health. 2020;17:10.

34. Busico M, Intile D, Sivori M, Irastorza N, Alvarez AL, Quintana J, Vazquez L, Plotnikow G, Villarejo F, Desmery P. Risk factors for worsened quality of life 
in patients on mechanical ventilation. a prospective multicenter study. Med Intensiva. 2016;40:422-30.

35. Pita-Romero R, Leal S, Sanduende Y, Rodrıguez A, Nieto C, Vilas E, Ochoa M, Cid M, Seoane-Pillado T. Quality of life, functional status, and persistent symptoms after intensive care of COVID-19 patients. Br J Anaesthesia. 2020;126(3):e110-3.

\section{Publisher's Note}

Springer Nature remains neutral with regard to jurisdictional claims in published maps and institutional affiliations. 